\title{
An interdisciplinary capstone experience integrates science, technology, business, and law for joint MS students in environment and resources at Stanford University
}

\author{
Kathleen A. Phillips • Helen J. Doyle
}

Published online: 18 August 2011

(C) The Author(s) 2011. This article is published with open access at Springerlink.com

\begin{abstract}
Professional school students who are simultaneously pursuing MBA, JD, or MD degrees with an MS in environment and resources appreciate the opportunity to apply what they have learned in the classroom to real environmental problems. These capstone projects allow students to combine their graduate work into one integrated project that is both an excellent educational component of their joint MS curriculum and a practical, real-world experience that they can highlight and discuss with potential employers. Here, we discuss the development and implementation of a new capstone project requirement and its associated seminar course that is part of the joint MS curriculum at Stanford University's Emmett Interdisciplinary Program in Environment and Resources (E-IPER). The course thus far has produced a range of exciting projects and results, and has allowed E-IPER's joint MS students to showcase the knowledge and analytical skills they have acquired to the wider environmental community at Stanford through the quarterly capstone symposium. In general, the students have appreciated the opportunity to integrate their educational work and go deeper on a project that is of personal interest and relevance.
\end{abstract}

Keywords Interdisciplinary environmental business studies · Interdisciplinary environmental law studies . Capstone projects $\cdot$ Environmental Master's degree projects

\footnotetext{
K. A. Phillips $(\bowtie) \cdot$ H. J. Doyle

Emmett Interdisciplinary Program in Environment and Resources, School of Earth Sciences, Stanford University

473 Via Ortega, MC 4210

Stanford, CA 94305, USA

e-mail: kphill@stanford.edu

H. J. Doyle

e-mail: hdoyle@stanford.edu
}

\section{Introduction}

The capstone project requirement for the joint Master of Science in environment and resources degree in Stanford University's Emmett Interdisciplinary Program in Environment and Resources (E-IPER) was developed as a new part of the curriculum during the 2009-2010 academic year. The first four projects were completed in Spring 2010, and two more cohorts of students completed 13 projects in the 2010-2011 academic year. The capstone requirement was developed to enhance the curriculum with a real-world project component that allows students to integrate and showcase the science, engineering, technical, and professional skills that they gained in their graduate work. The projects are similar to a Master's thesis in that they are meant to be encapsulating projects that integrate a student's coursework, but the format is much more flexible to allow students to complete a project, including a final product, that is of practical interest and relevance to their career plans. The complete E-IPER Capstone Project Guidelines are available online: http://e-iper.stanford.edu/academics/joint-ms/ joint-ms-capstone-project.

The capstone project requirement includes an associated seminar course that is worth three quarter units of academic credit, co-taught by E-IPER's faculty director and joint MS program manager. Projects are student selected, and students may work in a group of up to three or individually. Students generally complete their projects over one quarter, although they may elect to spread out their project work over two quarters if their schedules allow. The capstone seminar is run as a facilitated independent study course, and students give a final presentation of their work at the end of the quarter during a public capstone project symposium. 


\section{Background}

Context in the curriculum

Stanford University is increasingly interested in developing and sustaining interdisciplinary educational programs for both undergraduate and graduate students. The E-IPER program is one such initiative. The program began in 2001 with an interdisciplinary Ph.D. program in environment and resources, and a joint MS program for current Stanford professional school students in the university's business, law, or medical schools. Today the program supports $35 \mathrm{Ph}$. D. students and 45 joint MS students, with approximately 3/4 of the joint MS students coming from Stanford's Graduate School of Business, one student from the School of Medicine, and the rest of the students from Stanford Law School. These joint MS students complete their MS coursework simultaneously with their MBA, JD, or MD coursework, and are generally with E-IPER for 1-2 years.

The joint MS curriculum (http://e-iper.stanford.edu/ academics/joint-ms/joint-ms-curriculum) provides the structure for a rigorous and coherent Master's degree program, while still allowing students from a multitude of backgrounds the flexibility to choose their own path through the wide array of environment and resources courses offered at Stanford. The Capstone project fits into the curriculum as a required course, a graduation requirement, and a valuable professional development opportunity. Each student must participate in the seminar course, completing and publically presenting their capstone project integrating their E-IPER and professional school work and, for many students, the project helps focus their presentation about the joint degree when they enter the job market.

The E-IPER capstone project requirement was developed after research into similar environmental Master's capstone requirements at peer institutions including the Nicholas School at Duke University, the Bren School at University of California (UC) Santa Barbara, the School of Natural Resources and Environment at University of Michigan, and Yale School of Forestry. We based part of our capstone project requirements on those of Duke University; the capstones at the other institutions required more time and resources that we were able to devote to our capstone project. Similar to the Nicholas School at Duke, our students select their own projects, define their methods for completing those projects, and prepare a detailed project proposal; however, most E-IPER students complete their projects in one quarter. Because our students do not graduate at the same time, we offer the capstone seminar twice per year, and thus, the experience is not as deep as those projects that run over multiple quarters or semesters such as the projects at UC Santa Barbara, University of Michigan, and Yale. The flexibility of the E-IPER capstone, however, allows us to accommodate a wide range of academic backgrounds and interests and different graduation schedules while still providing a real-world experience for each student.

\section{Logistical considerations}

Capstone projects are student selected, reducing logistical considerations for faculty and staff associated with soliciting projects and managing off campus partnerships. Generally, students come into the capstone seminar with several project ideas and are able to select an idea on which to focus with input from the capstone instructors and their advisors. The seminar class/section sizes are kept small to provide an opportunity for substantive peer review of each project by all other students in the section.

There is a Capstone Project Committee, made up of two to three faculty members representing the topic areas and professional schools of the students in the class each quarter. The Committee reviews, assesses, and ultimately approves all capstone project proposals. The Committee also provides troubleshooting support during the quarter if necessary and provides input on the final products and project presentations.

The E-IPER program has a grant to support the capstone projects, including a monetary prize for the Capstone project that best integrates students' science and professional school work in an innovative way each quarter. A public symposium is held where the students present their projects to the wider environmental campus community. The program also supports a fund to which students can apply for small grants to support materials, travel, and other resources needed for their capstone projects. These funds were secured from a private donor for the E-IPER program through Stanford's School of Earth Sciences development office.

\section{The Capstone/Practicum Experience}

Learning goals

The major learning goal for the capstone projects is for students to integrate their science, engineering, and technology coursework with their professional school work into a final encapsulating project that addresses a real-world environmental problem or opportunity. Each student also gains skills in scientific research and documentation, for example by producing an annotated bibliography of their project-related research. Throughout the capstone seminar students also practice peer review and presentation skills by evaluating and providing constructive criticism and suggestions on each other's work. 


\section{Structure}

Capstone projects are initiated during student's last 1-2 quarters in the program. Projects are student selected and may grow out of previous coursework, a summer work experience, an independent study, or research with a faculty member or off campus client. All students are strongly encouraged to engage a project mentor. The capstone can be an opportunity for students to explore a potential career path, conduct research in an area of academic interest, or work on developing an entrepreneurial idea. Students generally come into the seminar with ideas for their capstone projects that they have previously discussed with the Joint MS Program Manager. Students may elect to work in a group or individually. The capstone seminar is roughly divided into three sections: (1) solidifying project ideas and preparing a proposal, guided by the seminar instructors; (2) independently conducting the project, and (3) reconvening as a class to prepare and present the final project to the wider Stanford environmental community. See Fig. 1 for a schematic of the capstone project structure.

E-IPER's joint MS students come from a wide range of academic and professional backgrounds with some students coming from undergraduate science or engineering majors and other students coming from liberal arts majors with little in the way of science or technical training. The flexible student-selected project format allows us to accommodate this range of backgrounds while still challenging each student academically. The academic rigor of each project is ensured through a highly structured proposal preparation and review process that requires students to clearly articulate the project goals, methods, and potential impact. Draft proposals are peer-reviewed, and final proposals are carefully reviewed by the Capstone Committee. Students pursue different paths as they complete their projects, from lab experimentation to policy analysis and interviews to market research and technical analyses.

Peer review is used throughout the capstone seminar. Because of the wide range of project topics in the class including science, business and law, the peer review portion of the seminar is extremely valuable. The seminar instructors have content knowledge in biology, ecology, and earth sciences and scientific research skills and offer their insights in these areas, while the students are able to offer each other their expertise in business and law. Interdisciplinary feedback helps to push the students into new territory and improves the overall project results, while also building positive community between the students as they become invested in one another's projects. For example, one of our business students, who was not well versed in environmental policy, was working on a project involving carbon credits. One of our law students in the same capstone seminar was able to share her expertise on carbon credits and introduce the business student to a
Fig. 1 Schematic of the E-IPER capstone project structure. This diagram illustrates the path that E-IPER joint MS students take to complete their capstone projects, including the capstone seminar. Ideally, students complete this process during their last two quarters in the program
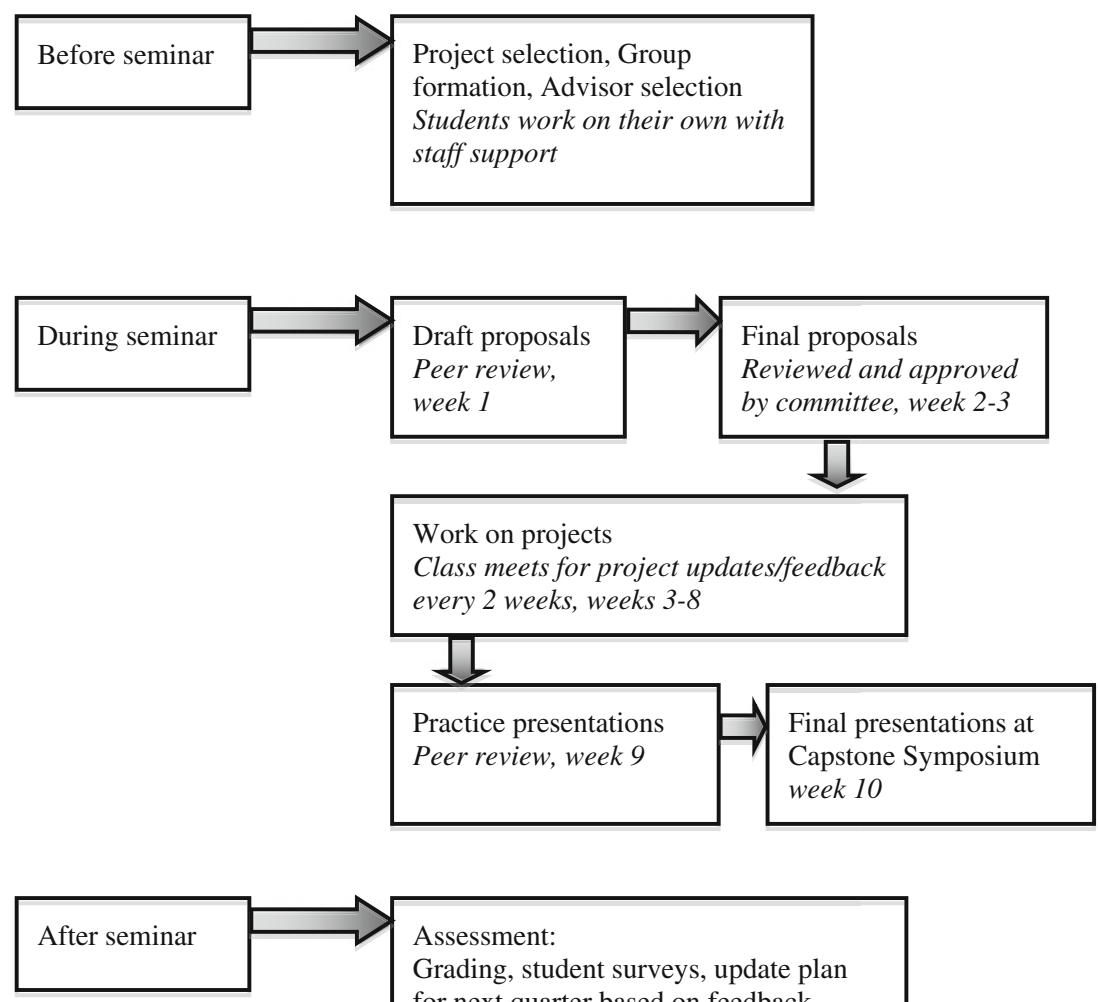

Assessment:

Grading, student surveys, update plan for next quarter based on feedback. 
relevant faculty member at the law school. These connections helped to improve the business student's overall learning and capstone project. During seminar meetings, all students give project updates to the group and mention any problems or questions they have, and these updates regularly result in a helpful exchange between students.

Students are given detailed guidelines for preparing project proposals once they have solidified their project ideas, and the second seminar meeting is devoted to peer review of draft proposals. The seminar instructors also provide written feedback to each student. They are then encouraged to incorporate the feedback into their final project proposals that are submitted to the Capstone Committee for review. One seminar session is devoted to skills development on scientific research sources, preparing an annotated bibliography and proper use and referencing of scientific and technical figures. Students then begin independent work on their projects.

The seminar does not meet regularly as a class during the middle of the quarter, but the instructors are available to the students for assistance on their projects. Students submit biweekly project updates detailing progress on their projects and any problems or barriers to progress they encountered and a draft of their annotated bibliographies. The class meets occasionally to discuss project updates and exchange experiences. The seminar reconvenes during the last week of the quarter for peer review of practice presentations. Each student, or group of students, then delivers a final $10-15$ min presentation on their project during the capstone project symposium, which is open to the wider Stanford community.

\section{Assessments and products}

As a part of the project, each student creates a final product. The form of the final product is chosen by the student and approved in the project proposal process. Examples of final products include reports, papers for publication, business plans, materials for use in obtaining funding for a new business idea from venture capital firms, etc. The final product is turned in at the end of the quarter and is assessed based on its overall quality and contribution to the student's field of interest. The seminar is graded on a credit/no credit basis with credit being awarded for successful completion of the proposed capstone project including submission of a final product and a community presentation of the project.

Outcomes of the capstone projects have varied, but some success stories include a student who launched his own energy efficiency company for which he prepared a business plan for his capstone project. One student used his capstone project as an opportunity to work with an energy storage company, gaining skills in market research by interviewing utility companies on their energy storage needs. Another student used her capstone project to do indepth research into future opportunities for nuclear energy. This student began her joint MS program with an interest in nuclear energy technologies and market opportunities, but Stanford does not offer much in the way of coursework on the technical side of nuclear energy, so she used the capstone project, in part, to fill this knowledge gap in her joint MS program. She proposed conducting research into the market for nuclear energy in the USA, focusing on small modular nuclear reactors (SMR), a new technology currently in development. She researched the technological, economic, and environmental viability of these reactors. During her research, she talked with three different companies currently developing SMRs, conducted literature research, and spoke with relevant faculty on campus in the policy and technical fields. The final product was an indepth written report. In her final presentation, the student gave a very clear explanation on how nuclear reactors work and the technology behind the SMR as well as a frank assessment of the economic viability and environmental pluses and minuses associated with building more nuclear power plants in the USA. She also won the capstone project prize for that quarter for her work.

Because the capstone project requirement is new, we do not yet have any long-term assessments of the impacts of the project on our students. We survey the students on their experiences in the capstone seminar, and we also conduct program surveys of all our graduates, where we ask students about their experience with the capstone project. Thus far, the majority of students have reported that the capstone project enhanced their joint MS degree program and gave them the opportunity to integrate their professional school and environment and resources work.

\section{Challenges and lessons learned}

We continue to learn and seek ways to improve the capstone experience for students each quarter. We have found that it is important for students to select their own projects so that they are invested and are working on something that is relevant to their educational and career goals. This also allows us to accommodate the wide range of academic backgrounds in our program. The peer review portion of the seminar has proven to be quite successful, as the students are open with each other and do a great job of providing helpful suggestions on each other's work. Peer review also helps to cover the wide range of content in an interdisciplinary setting, where it is not possible to have a faculty instructor representing all topic areas in which students are working. The structure and guidelines around the project proposals help students to focus their ideas and propose projects that are both interesting and tractable. 
Some challenges we have encountered thus far include helping the students find appropriate faculty mentorship for their projects. We do not assign project advisors, but rather strongly encourage students to seek out their own advisors in their areas of interest. This can sometimes be frustrating for students when their chosen faculty member is too busy to provide them with much one on one project mentorship. Faculty members are most interested in advising students on projects that are directly relevant to their own research or that might yield results that could help inform their research. We have enlisted an emeritus faculty member from the Civil and Environmental Engineering department to act as a senior advisor to our students who are interested in projects relating to energy, and this has been invaluable since at least half of our students share this interest. We sometimes struggle to find appropriate faculty mentorship for students with other interests.

We have also faced challenges in the area of assessment because the project topics are so varied, and we have offered the course for a credit/no credit grading option. We do find, however, that offering the seminar credit/no credit can produce a lower caliber of student work that we would otherwise expect with some students just doing the minimum amount of work to get credit while others work hard and produce excellent projects. In the 2011-2012 academic year, we are going to experiment with offering the seminar for a letter grade, with the bulk of the grade depending on class participation and peer review, timeliness of assignments, and the quality of the final presentation. We hope that this will increase students' motivation and raise the overall quality of all projects.

After the first quarter that we offered the capstone seminar, it became clear that the students did not have the literature research and documentation skills that we expected, so we instituted the requirement for each student to prepare an annotated bibliography, and we now spend time in the seminar going over proper scientific research and documentation, including proper use of scientific and technical figures in reports and presentations. We also provide examples of quality annotated bibliographies and well-done proposals from previous classes in order to set the bar for the caliber of work we expect from students.

For anyone considering offering a capstone project experience similar to ours at his/her own institution, we would offer the following advice. Make sure that the guidelines and requirements for the projects are clear, especially if students are selecting their own projects, to ensure that all projects reach a minimum level of complexity and technical competence. Involve as many relevant faculty members as possible as project advisors. The capstone experience is more beneficial to students to the extent that they can also develop a mentoring relationship with a faculty member of similar academic interests. Provide a forum for students to showcase their projects to a wider campus and/or public community, as this helps students to place their work in a larger context, gain experience presenting technical information to mixed audiences, and could also generate new project ideas and collaborations between interested audience members and students who might not have otherwise met.

Acknowledgments We would like to acknowledge the FeigenbaumNii Foundation for their support of the capstone projects and symposium. We would also like to thank the faculty and students who have contributed to the development and continual improvement of the capstone project requirements.

Open Access This article is distributed under the terms of the Creative Commons Attribution Noncommercial License which permits any noncommercial use, distribution, and reproduction in any medium, provided the original author(s) and source are credited. 